\title{
Determination of carotenoids in flowers and food supplements by HPLC-DAD
}

\author{
Petra Pavelková, Aleš Krmela, Věra Schulzová \\ Department of Food Analysis and Nutrition, University of Chemistry and Technology, Prague, \\ Technická 3, 166 28, Prague, Czech Republic \\ pavelkova.petra@seznam.cz
}

\begin{abstract}
Marigold flowers (Tagetes patula and Calendula officinalis) were chosen for analysis because they are the most often used source of lutein and its isomer zeaxanthin for the production of food supplements on the Czech market. Direct extraction and extraction with alkaline hydrolysis were compared to detect free or bound carotenoids. For carotenoid separation, C18 and C30 columns were used. A new method for determination of carotenoid content in food supplements in form of capsules has been developed and validated. All matrices were analysed by high-performance liquid chromatography with diode array detection (HPLC-DAD). It has been found that alkaline hydrolysis is required for both Marigold flowers and food supplements to release lutein from ester bonds to fatty acids. In Calendula officinalis lutein in the concentration of $807-1472 \mathrm{mg} \cdot \mathrm{kg}^{-1}$ of dry matter was detected. Tagetes patula has been identified as a better lutein source with the content of 5906-8677 $\mathrm{mg} \cdot \mathrm{kg}^{-1}$ of dry matter. It has been found that the content of lutein and zeaxanthin in commercial food supplements (Lutein Complex Premium and Occutein Brillant) is consistent with the declared quantity. Linearity of the HPLC-DAD method ranged from $0.1-20 \mu \mathrm{g} \cdot \mathrm{mL}^{-1}$ with the limit of quantification (LOQ) of $1.7 \mathrm{mg} \cdot \mathrm{kg}^{-1}$ for lutein in Marigold flowers and $200 \mathrm{mg} \cdot \mathrm{kg}^{-1}$ in food supplements. Repeatability was $2.3 \%$ for lutein in all tested matrices.
\end{abstract}

Keywords: food supplements, HPLC-DAD, lutein, Marigold flowers, zeaxanthin

\section{Introduction}

Carotenoids are ubiquitous organic compounds, mainly of yellow, orange and red colour, soluble in fats and organic solvents (Watkins and Pogson, 2020). Currently, more than 1100 carotenoids are known (Yabuzaki, 2017). Several of these pigments are retinoids because of their vitamin A activity (Becerra et al., 2020; Watkins and Pogson, 2020).

From the chemical point of view, these compounds are predominantly tetraterpenes composed of eight isoprene units. In their chain, they have a conjugated double bond system representing a lightabsorbing chromophore that gives carotenoids their characteristic colour (Rodriguez-Amaya, 2019). Carotenoids are identified from their visible absorption spectrum (Saini et al., 2015).
Carotenoids are divided into two basic groups carotenes and xanthophylls. Carotenes are formed by a hydrocarbon chain (lycopene, $\alpha$-carotene, $\beta$-carotene) while xanthophylls are oxidized derivatives of carotenes ( $\beta$-cryptoxanthin, lutein, zeaxanthin) (Becerra et al., 2020).

Lutein (Fig. 1) and its isomer zeaxanthin (Fig. 2) are natural pigments of yellow colour.

These substances are labile and they easily isomerize and degrade in the presence of light, heat and oxygen; thus, preventive procedures have to be taken to adapt both storage and processing conditions (Saini et al., 2015; Becerra et al., 2020). Human bodies are not able to synthesize carotenoids themselves, so they have to take them in food or food supplements (Woodside et al., 2015). The most important sources of xanthophylls include fruits, vegetables,<smiles>CC1=C[C@H](O)CC(C)(C)[C@H]1/C=C/C(C)=C/C=C/C(C)=C/C=C/C=C(C)/C=C/C=C(C)/C=C/C1=C(C)C[C@@H](O)CC1(C)C</smiles>

Fig. 1. Structural formula of lutein.<smiles>CC1=C(/C=C/C(C)=C/C=C/C(C)=C/C=C/C=C(C)/C=C/C=C(C)/C=C/C2=C(C)C[C@H](O)CC2(C)C)C(C)(C)C[C@H](O)C1</smiles>

Fig. 2. Structural formula of zeaxanthin. 
and some plant species such as Marigold flowers (Lin et al., 2015; Watkins and Pogson, 2020). Tagetes erecta is the most often used source of lutein and zeaxanthin for food supplements production on the Czech market. A typical example is Lutein PLUS (Walmark), Lutein Premium (Generica), Lutein-z (Jamieson) or ProVision (Vitaland). Lutein is present in free form or bound to fatty acids via an ester bond (Abdel-Aal and Rabalski, 2015). It is used as a food colourant (E 161b) but also as an additive in fodder for hens or in the food industry as a food supplement mainly for its antioxidant properties (Ree, 2006; Marounek and Pebriansyah, 2018). A link between lutein intake and its positive effect on vision has been shown many times. The central part of retina, called macula lutea (yellow spot), is responsible for high visual acuity and it is composed of lutein, zeaxanthin and meso-zeaxanthin, in common called macular pigment (Bernstein et al., 2016), which plays an important role in protecting the eye from UV and phototoxic blue light (Peng et al., 2016). Scientists conducted an experiment in the eyes of monkeys proving that those lacking xanthophylls in the diet do not have these pigments detectable in serum. However, when lutein and zeaxanthin were incorporated in their diet despite lifetime deficiency, the macular pigment quickly returned to normal levels (Tsao et al., 2007). Lutein has a preventive effect against diseases such as cataract or age-related macular degradation (AMD) (Bernstein et al., 2016; Nwachukwu et al., 2016). The major risk factor affecting AMD is oxidative stress. Taiwanese scientists have found that if people with early stage AMD receive $12 \mathrm{mg}$ of lutein and $2 \mathrm{mg}$ of zeaxanthin daily for five months, antioxidant activity improves. This study also claims that long-term consumption can suppress oxidative stress and thereby avoid AMD (Peng et al., 2016). Lutein is also involved in the skin protection from UV radiation, positively affects cognitive functions, helps reducing the risk of cardiovascular disease and also strengthens immunity (Mares-Perlman et al., 2002; Nwachukwu et al., 2016; Buscemi et al., 2018). Despite their many beneficial effects, the European Food Safety Authority (EFSA) has not approved any health claims concerning lutein and zeaxanthin. There is not enough evidence to prove a cause and effect relationship between the consumption of lutein and subsequent normal vision (EFSA Panel on Dietetic Products, Nutrition and Allergies, 2010). The recommended daily dose is not specified.

For the determination of carotenoids in plant matrices and food supplements, the most frequently used method is HPLC-DAD (or UV/VIS) (Aman et al., 2004; Abdel-Aal and Rabalski, 2015; Bernstein et al., 2016). In the past, mainly normal phase HPLC was used, while nowadays reverse phase HPLC with analytical columns C18 and C30 are used for their separation (Amorim-Carrilho et al., 2014; Fratianni et al., 2015). C18 column is not capable to separate structural and geometrical isomers so it cannot be used for the separation of lutein and zeaxanthin due to their co-elution. Column C30 is the best choice for efficient separation of isomers even though their retention times are similar (AmorimCarrilho et al., 2014). Carotenoid identification is also possible using tandem mass spectrometry (de Rosso and Mercadante, 2007; Tsiaka et al., 2018; Zhang et al., 2019) or thin layer chromatography (TLC) combined with UV/VIS visualization and densitometry (Altemimi et al., 2015).

\section{Materials and Methods}

\section{Chemicals and standards}

Standard of lutein (purity $95 \%$ ) was purchased from Labicom (Czech Republic) and $\beta$-carotene (purity $\geq 99 \%$ ) from Sigma-Aldrich (Germany). Sodium hydroxide and sodium sulphate were obtained from Lach-Ner s.r.o. (Czech Republic), ethanol, methanol, n-hexane and methyl tert-butyl ether (MTBE) from Merck KGaA (Germany), acetonitrile, tertbutyl-hydroxytoluene (t-BHT) from Sigma-Aldrich (Germany) and acetone from Penta Chrudim (Czech Republic). Water was purified using a Milli-Q Ultrapure water purification system from Millipore (Germany).

\section{Sample preparation}

The first group of analysed samples consisted of Marigold flowers used commonly as carotenoid source for food supplement preparation. Calendula officinalis and Tagetes patula, specifically their blooms from the Institute of Botany in Prague, were stored in a freezer $\left(-20^{\circ} \mathrm{C}\right)$ before the analysis and Calendula officinalis tea from blooms manufactured by Mediate, s.r.o. was also analysed. The samples were thoroughly homogenized in a mortar without using a solvent. Half a gram of each sample was weighed into a $15 \mathrm{ml}$ plastic cuvette wrapped in aluminium foil.

Food supplements, more specifically capsules (Lutein Complex Premium, Ocutein Brillant), available on the Czech market were analysed for carotenoid content, weighed - first the whole capsule and then just the dried shell purified with hexane, cut with a sharp scalpel and 3-5 $\mathrm{mg}$ of the sample was transferred into a $50 \mathrm{ml}$ cuvette wrapped in aluminium foil.

\section{Standard preparation}

The stock solution of lutein for carotenoid analysis was prepared at the concentration of $100 \mu \mathrm{g} \cdot \mathrm{mL}^{-1}$, 
concentrations of the working solution in ethanol $(0.2 \%$ t-BHT)/acetone $(6: 4 ; \mathrm{v} / \mathrm{v})$ solvent mixture ranged from 0.1 to $20 \mu \mathrm{g} \cdot \mathrm{mL}^{-1}$. The working solution was always prepared fresh using the stock solution stored in a freezer $\left(-20^{\circ} \mathrm{C}\right)$.

\section{Determination of dry matter}

Homogenised flower samples were dried to a constant weight at $105^{\circ} \mathrm{C}$.

\section{Extraction of lutein, zeaxanthin and $\beta$-carotene}

The first method used was direct extraction for blooms of Calendula officinalis and Tagetes patula. First, $2 \mathrm{ml}$ of the mixture of ethanol $(0.2 \%$ t-BHT)/n-hexane - 4:4 (v/v) were added to the weighed sample. The cuvette was capped, coated with parafilm and shaken for 30 minutes on a shaker. Then, $2 \mathrm{ml}$ of deionised water were used to separate the layers and the mixture was centrifuged (6000 RPM, $5{ }^{\circ} \mathrm{C}, 5 \mathrm{~min}$ ). Subsequently, the upper hexane layer was removed into a $50 \mathrm{ml}$ heart flask and re-extraction of the ethanol portion was repeated with another $4 \mathrm{ml}$ of $\mathrm{n}$-hexane (followed by shaking, centrifugation and removal of the upper hexane layer). The re-extraction was carried out until the upper hexane layer was colourless. All hexane extracts were combined and evaporated on the evaporator at $30{ }^{\circ} \mathrm{C}$, followed by slow evaporation to dryness in a stream of nitrogen gas. The residue was reconstituted in a $10 \mathrm{ml}$ mixture of ethanol $(0.2 \%$ t-BHT)/acetone $-6: 4(v / v)$ and filtered through a microfilter on a centrifuge (10000 RPM, $5{ }^{\circ} \mathrm{C}, 3 \mathrm{~min}$ ) to obtain approximately $1 \mathrm{ml}$ of solution which was transferred to an amber vial and prepared for HPLC analysis.

The second extraction method for blooms of Calendula officinalis and Tagetes patula involved alkaline hydrolysis. First, $2 \mathrm{ml}$ of the mixture of ethanol $(0.2 \%$ t-BHT)/acetone $-6: 4(v / v)$ and $2 \mathrm{ml}$ of $\mathrm{n}$-hexane were added to the weighed sample followed by vortexing for $5 \mathrm{~min}$. Then, $6 \mathrm{ml}$ of n-hexane and then $5 \mathrm{ml}$ of the mixture of ethanol $(0.2 \% \mathrm{t}-\mathrm{BHT}) /$ acetone $-6: 4(v / v)$ were added and vortexing was repeated for another $5 \mathrm{~min}$. Afterward, $5 \mathrm{ml}$ of methanolic potassium hydroxide (conc. $20 \mathrm{~g} \cdot \mathrm{l}^{-1}$ ) were added to saponify the whole suspension. Cuvettes covered in aluminium foil and filled with nitrogen gas (to maintain inert atmosphere in the cuvette) were kept at room temperature (approx. $23{ }^{\circ} \mathrm{C}$ ) overnight. The next day, $10 \mathrm{ml}$ of $\mathrm{n}$-hexane and $10 \mathrm{ml}$ of a solution of $\mathrm{Na}_{2} \mathrm{SO}_{4}$ in deionized water (conc. $100 \mathrm{~g} \cdot \mathrm{l}^{-1}$ ) were added to the mixture. The cuvette covered with parafilm was intensively hand-shaken for $2 \mathrm{~min}$ and then centrifuged (10000 RPM, $\left.5{ }^{\circ} \mathrm{C}, 5 \mathrm{~min}\right)$. The upper hexane layer was removed into a $50 \mathrm{ml}$ heart flask and then the procedure was exactly same as in direct extraction.

Direct extraction and alkaline hydrolysis extraction were used also for the analysis of food supplements. The procedures were almost identical to the extraction methods for Marigold flowers, the only difference was the use of hexane/acetone $-1: 1(v / v)$ with the addition of t-BHT $(0.2 \mathrm{~g}$ per $100 \mathrm{ml}$ solution) as an extracting agent.

\section{HPLC-DAD determination}

High-performance liquid chromatography coupled with a diode array detector (HPLC-DAD) was used for chromatographic separation and sample analysis (Agilent Technologies 1200 series, Santa Clara, CA, USA). The separation of carotenoids was carried out using analytical column Poroshell 120 EC-C18 $(2.1 \times 100 \mathrm{~mm}$; $2.7 \mu \mathrm{m})$ at the column temperature of $30{ }^{\circ} \mathrm{C}$ and the flow rate of $0.5 \mathrm{ml} \cdot \mathrm{min}^{-1}$. The mobile phase was composed of $100 \%$ acetonitrile (A) and $90 \%$ acetonitrile in deionized water (B). Gradient elution was used (0-2 min for $100 \% \mathrm{~B}, 5-28 \mathrm{~min}$ for $0 \% \mathrm{~B}, 28.5-30 \mathrm{~min}$ for $100 \% \mathrm{~B}$ ). The injection volume was $3 \mu \mathrm{L}$. As lutein and zeaxanthin are not separated in the C18 column, the C30 column $(3.0 \times 100 \mathrm{~mm} ; 3 \mu \mathrm{m}, \mathrm{YMC}$, Japan $)$ was also used to determine the ratio of lutein and zeaxanthin in all matrices. Column temperature was $35^{\circ} \mathrm{C}$, flow rate was $0.4 \mathrm{ml} \cdot \mathrm{min}^{-1}$, injection volume was $3 \mu \mathrm{l}$ and mobile phase consisted of $\mathrm{MeOH} / \mathrm{MTBE} /$ $\mathrm{H}_{2} \mathrm{O}$ in the ratio of $81: 15: 4, v / v / v(\mathrm{~A})$ and $\mathrm{MeOH} /$ $\mathrm{MTBE} / \mathrm{H}_{2} \mathrm{O}, 7: 90: 3, v / v / v(\mathrm{~B})$. Gradient elution was also used $(0-10 \mathrm{~min}$ for $0 \% \mathrm{~B}, 45 \mathrm{~min}$ for $56 \% \mathrm{~B}, 50 \mathrm{~min}$ for $100 \% \mathrm{~B}, 55-60 \mathrm{~min}$ for $0 \% \mathrm{~B}$ ). Carotenoids were detected at the wavelengths of $444 \mathrm{~nm}$ - lutein and zeaxanthin, and $450 \mathrm{~nm} \mathrm{-}$ $\beta$-carotene. The identification was performed by comparing the retention times of chromatograms and spectra of the measured samples with the standards of lutein and $\beta$-carotene. The external calibration method was used for quantification. Zeaxanthin was quantified on the lutein standard.

\section{Methods performance characteristics}

Response of the detector in the used calibration range of $0.1-20 \mu \mathrm{g} \cdot \mathrm{ml}^{-1}$ was linear. Detection limit (LOD) for lutein and $\beta$-carotene in Marigold flowers and food supplements was $0.1 \mu \mathrm{g} \cdot \mathrm{ml}^{-1}$, determined as the lowest point on the calibration line. Repeatability was expressed as a relative standard deviation (RSD). For the finally used method with alkaline hydrolysis, RSD values were $2.3 \%$ for lutein and $5.1 \%$ for $\beta$-carotene in Marigold flowers and $2.3 \%$ for lutein in food supplements. Limit of quantification (LOQ) was recalculated per kilogram of the 
sample according to the weight and performed extraction procedure to be $1.7 \mathrm{mg} \cdot \mathrm{kg}^{-1}$ for lutein and $7.3 \mathrm{mg} \cdot \mathrm{kg}^{-1}$ for $\beta$-carotene in Marigold flowers. In case of food supplements, LOQ was quite high, specifically $200 \mathrm{mg} \cdot \mathrm{kg}^{-1}$ for lutein, which corresponds to $0.25 \mathrm{mg}$ per one Lutein Complex Premium capsule weighing approximately $1.27 \mathrm{~g}$.

\section{Results and discussion}

The performed experiments aimed to determine the content of free and bound lutein/zeaxanthin in matrices used for the production of food supplements (Calendula officinalis, Tagetes patula) and the content of these xanthophylls in food supplements as well as to compare the determined levels with the producer's declaration. Supplements Lutein Complex Premium and Ocuttein Brillant were chosen for the analysis. These food supplements are very popular and often used by the Czech population, which is the main reason why the analysis was focused on them.

The first analysed matrices were dried and frozen blooms of Calendula officinalis. In both cases, satisfactory extraction yields were achieved using minimum three repeated extractions, both for direct extraction and for the alkaline hydrolysis process. Dried blooms of Calendula officinalis purchased as tea had very low water content of approximately $7 \%$. The water content of frozen flowers varied between 81-86\%. To compare results obtained in different matrices, the carotenoid content was expressed on the dry matter of the sample. C18 column was sufficient for the determination of total lutein and zeaxanthin content as the time needed for separation is significantly shorter, approximately twice, compared to the C30 column separation. It has been found that in case of Calendula officinalis, the inclusion of an alkaline hydrolysis step is necessary. In dried flowers used for tea preparation, lutein content was determined to be $11.9 \mathrm{mg} \cdot \mathrm{kg}^{-1}$ of dry matter by direct extraction. After alkaline hydrolysis, the content increased approximately three times compared to the direct extraction method, to $46.0 \mathrm{mg} \cdot \mathrm{kg}^{-1}$ of dry matter. The overall relatively low detected content of this xanthophyll was probably due to its degradation during flower drying. Based on the determined content it can be claimed that Calendula officinalis tea is not a very good source of xanthophylls. Lutein content in frozen flowers ranged from 807 to $1472 \mathrm{mg} \cdot \mathrm{kg}^{-1}$ of dry matter. In comparison with literature data, the content was also expressed on fresh matter ranging from 122 to $253 \mathrm{mg} \cdot \mathrm{kg}^{-1}$. Lower, but also similar xanthophyll contents were determined by Romanian scientists who analysed four different varieties of Calendula officinalis. The lutein content ranged from 40 to $256 \mathrm{mg} \cdot \mathrm{kg}^{-1}$ (Pintea et al., 2003). On the other hand, Brazilian scientists have determined in Calendula officinalis lutein content of $298 \mathrm{mg} \cdot \mathrm{kg}^{-1}$ (Manke Natchigal et al., 2010). In literature, a significant difference between the lowest and highest concentration of lutein can be observed, which is probably due to various varieties, different geographical and climatic growth conditions or different way of storage. During our experiment, Calendula officinalis extracts were also analysed on a C30 column and the approximate lutein to zeaxanthin ratio was found to be 14:3. After the inclusion of the alkaline hydrolysis step, there was no significant increase in the $\beta$-carotene content. However, the used method included alkaline hydrolysis for all determined carotenoids. In Calendula officinalis dried blooms, the content of $\beta$-carotene was determined to be $13.8 \mathrm{mg} \cdot \mathrm{kg}^{-1}$ of dry matter, in frozen flowers it ranged from $220-904 \mathrm{mg} \cdot \mathrm{kg}^{-1}$ of dry matter, expressed on fresh matter it was $32-155 \mathrm{mg} \cdot \mathrm{kg}^{-1}$. The measured data were compared with the available literature. The content determined by Romanian scientists ranged from $23-460 \mathrm{mg} \cdot \mathrm{kg}^{-1}$ (Pintea et al., 2003). It was found that the concentration range is wide, in Romanian varieties bought in specialized stores in France it is even wider than that determined in this study.

Another plant matrix analysed was frozen flowers of Tagetes patula with the water content of approximately $84-86 \%$. In this case, three extractions were also needed for the two tested extraction procedures. The inclusion of alkaline hydrolysis for extraction has been proven to be essential for this analysis. Fig. 3 shows chromatograms documenting the increase in the xanthophyll content after the inclusion of the alkaline hydrolysis step including the separation of isomers. Figure 4 shows the UV/VIS spectra of lutein and zeaxanthin.

The combined content of lutein and zeaxanthin ranged from 5906 to $8677 \mathrm{mg} \cdot \mathrm{kg}^{-1}$ of dry matter. Literature data for a Tagetes erecta cultivar harvested on Bali and called Mega Orange show lutein and zeaxanthin range from 8950 to $14550 \mathrm{mg} \cdot \mathrm{kg}^{-1}$ of dry matter. The content we determined was lower as well as that of another cultivar called Mega Gold also from Bali (2560-3730 $\mathrm{mg} \cdot \mathrm{kg}^{-1}$ of dry matter) (Kurniawan et al., 2019). The determined xanthophyll content was also expressed on fresh matter for comparison with the published literature data. Brazilian scientists determined lutein content in brown flowers of Tagetes patula to be $12306 \mathrm{mg} \cdot \mathrm{kg}^{-1}$ and in yellow flowers it was $597 \mathrm{mg} \cdot \mathrm{kg}^{-1}$ (Manke Natchigal et al., 2010). We determined higher lutein concentrations in comparison with the cited levels in yellow flowers, but lower than published for brown flowers. Lutein content in our samples ranged from 


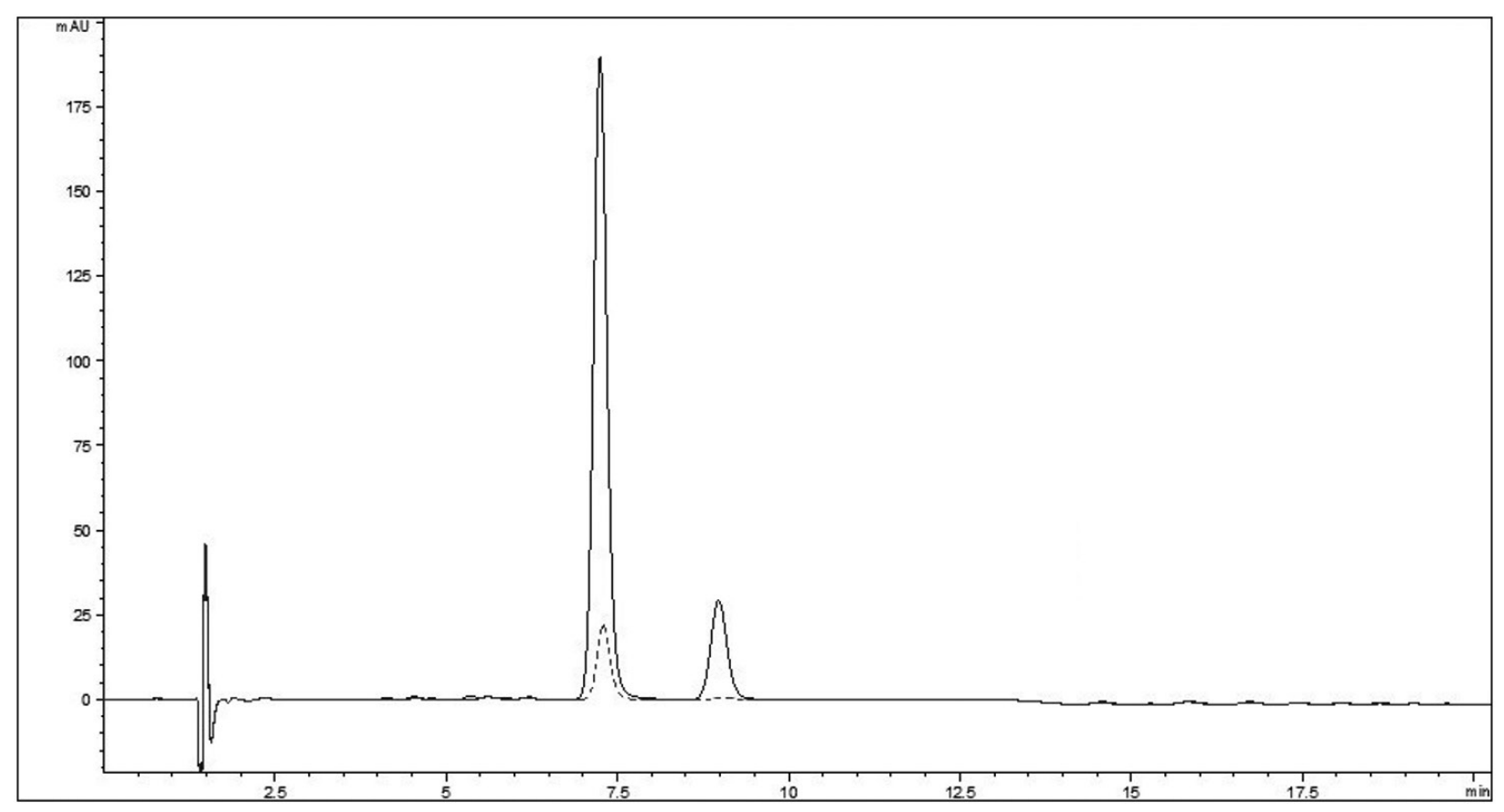

Fig. 3. Chromatograms of the Tagetes patula sample, comparison of direct extraction method (dashed line) and extraction with alkaline hydrolysis (solid line); C30 column, $\lambda=444 \mathrm{~nm}$.

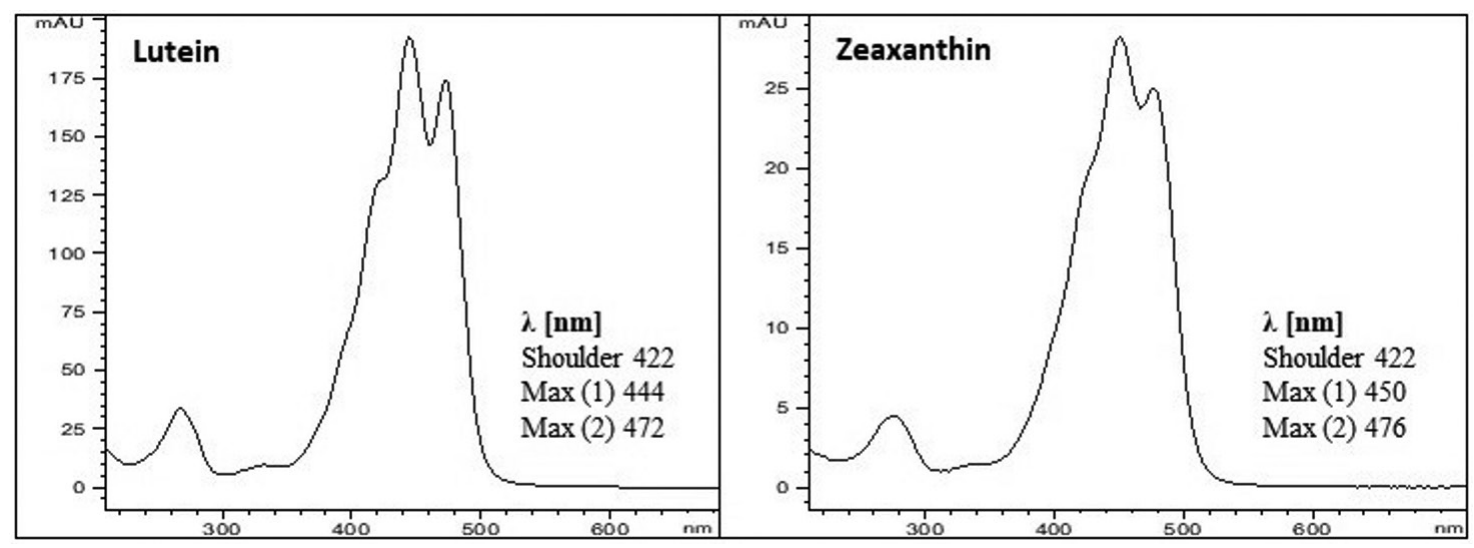

Fig. 4. UV/VIS spectra of lutein and zeaxanthin in Tagetes patula.

$850-1362 \mathrm{mg} \cdot \mathrm{kg}^{-1}$ of fresh matter. When separated on the C30 column, the lutein:zeaxanthin ratio of 24:1 was determined for Tagetes patula flowers. The average content of $\beta$-carotene was $467.5 \mathrm{mg} \cdot \mathrm{kg}^{-1}$ of dry matter in frozen flowers of Tagetes patula.

Due to its high lutein content, approximately six times higher than in Calendula officinalis, Tagetes patula is widely used for the production of food supplements. The advantage of this raw material is its good availability, low price and also high yields in cultivation.

Food supplements in form of capsules were also analysed within the experiments and an analytical method for their extraction has been developed and validated. The alkaline hydrolysis extraction procedure for plant matrices has been found to be unsuitable for food supplements in form of capsules since it results in lower yields than the extraction procedure based on the published article (Aman et al., 2004). In our case, the vortex was replaced by a shaker (1800 RPM) mentioned in the article, a mixture of BHA and $\mathrm{BHT}$ was recommended as an antioxidant but only BHT was used. Due to the lack of accurate information in the experimental part, the procedure was linked to the alkaline hydrolysis extraction procedure for plant matrices mentioned in the experimental part. The resulting modified and subsequently validated method for food supplements is described in details in the experimental part.

In order to optimize the extraction procedure with alkaline hydrolysis, a sample of $50 \mathrm{mg}$ was initially selected but the carotenoid content was too high and no decolourisation of the extracted sample was achieved even after nine re-extractions. At 


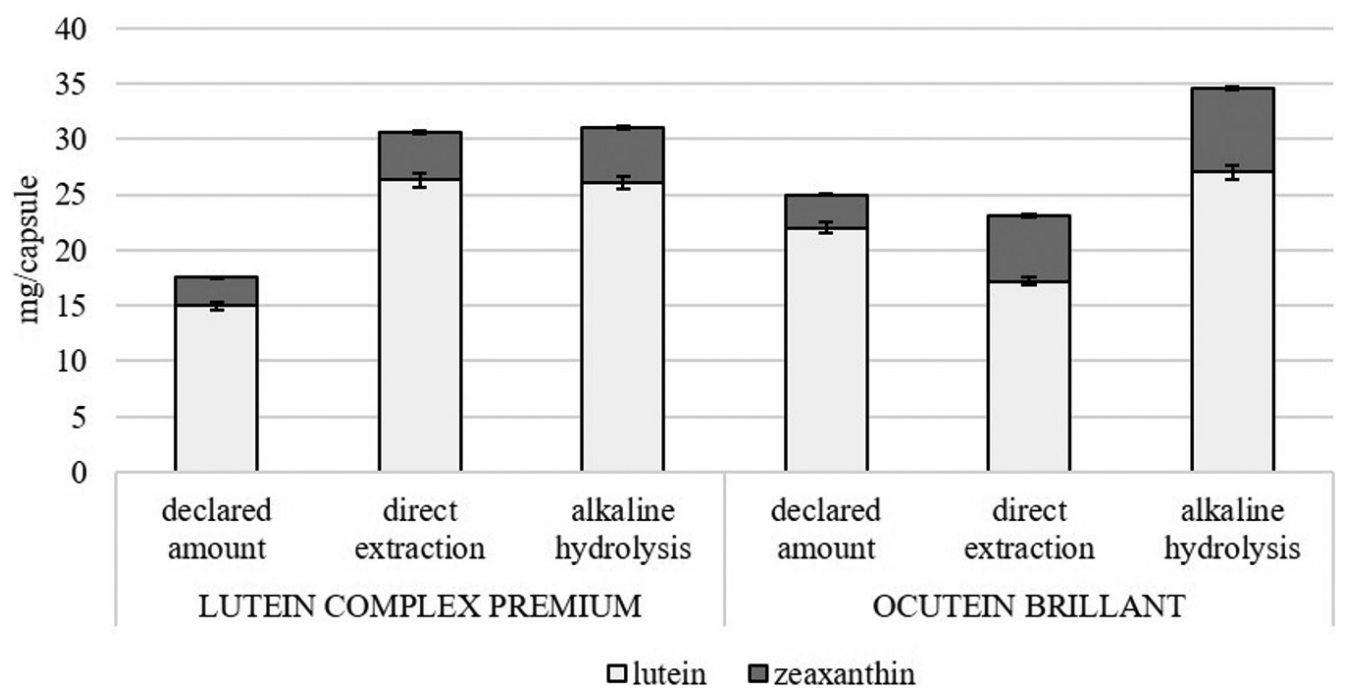

Fig. 5. Comparison of declared amounts of lutein and zeaxanthin with the values determined in the food supplements by direct extraction and extraction with alkaline hydrolysis.

the sample weight of $13 \mathrm{mg}$ and, seven repeated extractions provided the amount of lutein and zeaxanthin of $15.9 \mathrm{mg} \cdot$ capsule $^{-1}$ (declared amount $17.5 \mathrm{mg} \cdot$ capsule $\left.^{-1}\right)$ on the C18 column and the sample had to be diluted ten times prior to the analysis because the concentration was out of the linear range of the method. Reduced sample weight was used in other experiments and 3-5 mg proved to be an ideal weighed-in portion. Because of the homogeneous consistency of the sample, it can be easily weighed on an analytical balance, and it is sufficient to repeat the extraction step three to four times for the quantitative extraction of analytes. For the Lutein Complex Premium samples, the repeatability of the method, calculated as Relative Standard Deviation (RSD), was determined based on six parallel measurements performed.

Lutein content of $26.1 \mathrm{mg} \cdot$ capsule $^{-1}$ (declared value $15 \mathrm{mg} \cdot$ capsule $^{-1}$ ), zeaxanthin content of $4.9 \mathrm{mg} \cdot$ capsule $^{-1}$ (declared value $2.5 \mathrm{mg} \cdot$ capsule $\left.^{-1}\right)$ and $\beta$-carotene content of $6.6 \mathrm{mg} \cdot$ capsule $^{-1}(\mathrm{de}-$ clared $2 \mathrm{mg} \cdot$ capsule $^{-1}$ ) were detected using the C30 column for separation. Application of an extraction method without the alkaline hydrolysis step yielded approximately the same amount of lutein $\left(26.3 \mathrm{mg} \cdot\right.$ capsule $\left.^{-1}\right)$ and zeaxanthin $\left(4.3 \mathrm{mg} \cdot\right.$ capsule $\left.^{-1}\right)$ but the extraction procedure was more difficult and the sample had to be extracted more times to achieve its discolouration. For this reason, alkaline hydrolysis was also included in the analysis of the capsules. Carotenoid levels were analysed in food supplements with an expiration date of more than two years. It is likely that the manufacturer tries to ensure sufficient carotenoid content in the capsules at the end of the expiration date. The Lutein Complex Premium declaration states that lutein is present in the capsule in form of
$20 \%$ marigold extract.

The Ocutein Brillant food supplement analysed was also gel-like but with harder coating. In this sample, the extraction method without hydrolysis was not sufficiently effective as the matrix is very concentrated and despite the low sample weight it was not possible to extract carotenoids (until the sample was discoloured) even by multiple extractions. Therefore, a validated alkaline hydrolysis method described in the experimental part was used for both food supplements analysed with three to four extraction steps required to completely decolour the upper hexane layer. Experimentally, $27 \mathrm{mg} \cdot$ capsule $^{-1}$ of lutein (declared amount of $22 \mathrm{mg} \cdot$ capsule $^{-1}$ ) and $7.6 \mathrm{mg} \cdot$ capsule $^{-1}$ of zeaxanthin (declared $3 \mathrm{mg} \cdot$ capsule $^{-1}$ ) were determined. The expiration date for Ocutein Brillant capsules was more than two years after purchase at the store. The source of xanthophylls has not been reported for this food supplement.

A comparison of the declared and experimentally determined xanthophyll content of food supplements is summarized in Fig. 5.

\section{Conclusion}

For the determination of carotenoids in Marigold flowers (Tagetes patula and Calendula officinalis) as well as in food supplements, an analytical method including an alkaline hydrolysis step to release bound carotenoids from the matrix has been developed and validated. Lutein content determined by this method for Calendula officinalis was $807-1472 \mathrm{mg} \cdot \mathrm{kg}^{-1}$ of dry matter and that for Tagetes patula was $5906-8677 \mathrm{mg} \cdot \mathrm{kg}^{-1}$. For the separation of lutein and zeaxanthin, C30 analytical columns were used. 
Marigold flowers, especially Tagetes patula, are considered to be a good source of carotenoids for the production of food supplements for eye health but also as a suitable addition to feed for laying hens. The amount of xanthophylls was determined in food supplements, specifically capsules, and the levels were compared with the manufacturer's declaration. Food supplements manufacturers maintain the declared amounts and ensure that the product contains enough carotenoids throughout the expiration period.

\section{Acknowledgements}

This work was supported by METROFOOD-CZ research infrastructure project (MEYS Grant No: LM2018100) including access to its facilities; the Operational Programme Prague - Competitiveness (CZ.2.16/3.1.00/21537 and CZ.2.16/3.1.00/24503) and by the "National Program of Sustainability I" - NPU I (LO1601 - No.: MSMT43760/2015).

\section{References}

Abdel-Aal SM, Rabalski I (2015) Journal of Agricultural and Food Chemistry 63(44): 9740-9746.

Altemimi A, Lightfoot DA, Kinsel M, Watson DG (2015) Molecules 20(4): 6611-6625.

Aman R, Bayha S, Carle R, Schieber A (2004) Journal of Agricultural and Food Chemistry 52(20): 6086-6090.

Amorim-Carrilho KT, Cepeda A, Fente C, Regal P (2014) TrAC Trends in Analytical Chemistry 56: 49-73.

Becerra MO, Contreras LM, Lo MH, Díaz JM, Herrera GC (2020) Journal of Functional Foods 66: 103771.

Bernstein PS, Li B, Vachali PP, Gorusupudi A, Shyam R, Henriksen BS, Nolan JM (2016) Progress in Retinal and Eye Research 50: 34-66.

Buscemi S, Corleo D, Di Pace F, Petroni ML, Satriano A, Marchesini G (2018) Nutrients 10(9): 1321.

de Rosso VV, Mercadante AZ (2007) Journal of Agricultural and Food Chemistry 55(13): 5062-5072.
EFSA Panel on Dietetic Products, Nutrition and Allergies (2010) EFSA Journal 8(2): 1492.

Fratianni A, Mignogna R, Niro S, Panfili G (2015) Journal of Food Science 80(12): C2686-C2691.

Kurniawan JM, Yusuf MM, Azmi SS, Salim KP, Prihastyanti MNU, Indrawati R, Shioi Y, Limantara L, Brotosudarmo THP (2019) IOP Conference Series: Materials Science and Engineering 509: 012060.

Lin JH, Lee DJ, Chang JS (2015) Journal of the Taiwan Institute of Chemical Engineers 49: 90-94.

Manke Natchigal A, Oliveira Stringheta AC, Corrêa Bertoldi M, Stringheta PC (2010) ISHS Acta Horticulturae 939: 309-314.

Mares-Perlman JA, Millen AE, Ficek TL, Hankinson SE (2002) The Journal of Nutrition 132(3): 518S-524S.

Marounek M, Pebriansyah A (2018) Agricultura Tropica et Subtropica 51: 107-111.

Nwachukwu ID, Udenigwe CC, Aluko RE (2016) Trends in Food Science \& Technology 49: 74-84.

Peng ML, Chiu HF, Chou H, Liao HJ, Chen ST, Wong YC, Shen YC, Venkatakrishnan K, Wang CK (2016) Journal of Functional Foods 24: 122-130.

Pintea A, Bele C, Andrei S, Socaciu C (2003) Acta Biologica Szegediensis 47(1-4): 37-40.

Ree E (2006) The EFSA Journal 315(1): 1-12.

Rodriguez-Amaya DB (2019) Food Research International 124: 200-205.

Saini RK, Nile SH, Park SW (2015) Food Research International 76: 735-750.

Tsao R, Wang M, Deng Z (2007) American Chemical Society 956: 352-372.

Tsiaka T, Lantzouraki DZ, Siapi E, Sinanoglou VJ, Heropoulos GA, Calokerinos AC, Zoumpoulakis P (2018) Journal of Chromatography B 1096: 160-171.

Watkins JL, Pogson BJ (2020) Trends in Plant Science (19)30346-2: 1360-1385.

Woodside JV, McGrath AJ, Lyner N, McKinley MC (2015) Maturitas 80(1): 63-68.

Yabuzaki J (2017) The Journal of Biological Databases and Curation 2017(1): bax004.

Zhang L, Wang S, Yang R, Mao J, Jiang J, Wang X, Zhang W, Zhang Q, Li P (2019) Food Chemistry 289: 313-319. 